Published in final edited form as:

Accid Anal Prev. 2018 April ; 113: 47-53. doi:10.1016/j.aap.2017.12.021.

\title{
Diagnosed dementia and the risk of motor vehicle crash among older drivers
}

\author{
Laura A. Fraade-Blanar, MHS ${ }^{a}, 1$, Ryan N. Hansen, PhD, PharmD ${ }^{b}$, Kwun Chuen G. Chan, \\ PhD $^{b}$, Jeanne M. Sears, PhD ${ }^{d}$, Hilaire J. Thompson, PhD, RN, AGACNP-BC ${ }^{e}$, Paul K. Crane, \\ MD, MPH ${ }^{\dagger}$, and Beth E. Ebel, MD, MSc, MPH ${ }^{g}$ \\ aDoctoral Candidate, Department of Health Services, University of Washington, 1410 NE Campus \\ Parkway, Seattle WA, USA 98195-5852
}

${ }^{b}$ Research Assistant Professor, Department of Pharmacy, University of Washington; 1410 NE Campus Parkway, Seattle WA, USA 98195-5852. Adjunct Research Assistant Professor, Department of Health Services, University of Washington; 1410 NE Campus Parkway, Seattle WA, USA 98195-5852. Associate Faculty, Harborview Injury Prevention Research Center; 401 Broadway, Seattle, WA, USA 98122. Affiliate Investigator, Group Health Research Institute, 1730 Minor Ave, Seattle, WA USA, 98101

${ }^{\mathrm{C} A s s o c i a t e}$ Professor, Departments of Biostatistics, University of Washington, 1410 NE Campus Parkway, Seattle WA, USA 98195-5852. Associate Professor, Health Services, University of Washington, 1410 NE Campus Parkway, Seattle WA, USA 98195-5852

${ }^{\mathrm{d}}$ Research Associate Professor, Department of Health Services, University of Washington, 1410 NE Campus Parkway, Seattle WA, USA 98195-5852. Associate Faculty, Harborview Injury Prevention and Research Center, 401 Broadway, Seattle, WA, USA 98122. Adjunct Scientist, Institute for Work \& Health, Institute for Work \& Health, Ontario, Canada

eProfessor, Department of Biobehavioral Nursing and Health Informatics, University of Washington, 1410 NE Campus Parkway, Seattle WA, USA 98195-5852

fProfessor, Department of Medicine, University of Washington;, University of Washington, 1410 NE Campus Parkway, Seattle WA, USA 98195-5852. Adjunct Professor, Department of Health Services, University of Washington,, University of Washington, 1410 NE Campus Parkway, Seattle WA, USA 98195-5852

gProfessor, Department of Pediatrics, University of Washington and Seattle Children's Hospital; 1410 NE Campus Parkway, Seattle WA, USA 98195-5852. Adjunct Professor, Department of Epidemiology, University of Washington, 1410 NE Campus Parkway, Seattle WA, USA 98195-5852. Adjunct Professor, Department of Health Services, University of Washington, 1410 NE Campus Parkway, Seattle WA, USA 98195-5852

Corresponding author: Laura Fraade-Blanar, Harborview Injury Prevention \& Research Center, 325 Ninth Ave, Box 359960, Seattle, WA, USA, 98104-2499, Telephone: (206) 664-1106, lblanar@uw.edu.

${ }_{1}^{1}$ Present address: RAND Corporation, 1776 Main St, Santa Monica, CA 90401

Publisher's Disclaimer: This is a PDF file of an unedited manuscript that has been accepted for publication. As a service to our customers we are providing this early version of the manuscript. The manuscript will undergo copyediting, typesetting, and review of the resulting proof before it is published in its final citable form. Please note that during the production process errors may be discovered which could affect the content, and all legal disclaimers that apply to the journal pertain. 


\section{Abstract}

Older adults are an active and growing segment of drivers in the United States. We compared the risk of motor vehicle crash among older licensed drivers diagnosed with dementia to crash risk among older licensed drivers without diagnosis of dementia. This retrospective cohort study used data from Group Health $(\mathrm{GH})$, a Washington State health maintenance organization. Research participants were members of GH, aged 65 to 79 during the study who lived in Washington State from 1999-2009. Participant health records were linked with police-reported crash and licensure records. We estimated the risk of crash for older drivers diagnosed with dementia compared to older drivers without diagnosis of dementia using a Cox proportional hazards model with robust standard errors, accounting for recurrent events (crashes). Multivariable models were adjusted for age, sex, history of alcohol abuse or depression, comorbidities, and medications. There were 29,730 eligible individuals with an active driving license. Approximately $6 \%$ were diagnosed with dementia before or during the study. The police-reported crash rate was 14.7 per 1,000 driveryears. The adjusted hazard ratio of crash among older drivers with diagnosed dementia was 0.56 ( $95 \%$ CI $0.33,0.95$ ) compared to those without diagnosed dementia. On-road and simulator-based research showed older adults with dementia demonstrated impaired driving skill and capabilities. The observed lower crash risk in our study may result from protective steps to limit driving among older adults diagnosed with dementia. Future research should examine driving risk reduction strategies at the time of dementia diagnosis and their impact on reducing crash risk.

\section{Keywords}

older drivers; dementia; motor vehicle crash; cognition; survival analysis; longitudinal study design

\section{Introduction}

In 2015, 18\% of all licensed drivers in the United States (US) were aged 65 and above. ${ }^{1}$ There are health benefits of driving for older adults; and when driving is restricted, older adults are at greater risk of depression, social isolation, and entry into a long-term care facility. ${ }^{2-4}$ The annual passenger vehicle fatal crash involvement rate per vehicle miles traveled among drivers aged 65 and above is high, second only to drivers aged 16 to $29 .{ }^{5}$ Sustaining a motor vehicle crash may be devastating or fatal for frail older adults and places other road users at risk. ${ }^{6,7}$

One contributor to high crash rates per mile travelled may be cognitive decline or dementia. 2,3,8-10 Dementia is an umbrella term for a group of diseases and conditions wherein nerve cells in the brain die or no longer function normally. ${ }^{11}$ Cognitive function is a continuum with varying severity of symptoms and underlying pathologies. Individuals' cognitive states range from normal aging to prodromal dementia to diagnosed mild dementia to severe dementia. ${ }^{11-13}$ One of nine adults over aged 65 has Alzheimer's disease, the most common type of dementia, with prevalence increasing with age. The number of individuals with dementia is projected to rise as the US population ages. ${ }^{14}$ 
Simulator, lab, and road-based research has found that people with dementia have impaired driving skills, including impairments of hazard perception, processing of visual cues, attention, and decision-making. , $, 3,8-10,15$ Older drivers with cognitive decline may become lost, may struggle to negotiate intersections, and may stray from designated lanes and customary routes. $9,16-22$

Cognitive impairment has been previously found to be associated with higher crash risk, although the strength and significance of the association differed between studies. 2,3,9,10,18,19,21,23-29 Prior research on dementia and crash risk has been limited by the method of crash ascertainment, brief follow-up time, use of driving simulators, ${ }^{19,29,30}$ small sample sizes $2,3,9,10,15-17,21,27,31$ and/or measures of cognition with limited clinical relevance. ${ }^{15,27,28}$ Driving tests, ${ }^{10,12,16,25,27,29,30,32,33}$ subject perceived driving ability, ${ }^{3,32,34}$ recalled crash, $3,10,28,32,33$ and simulated driving studies ${ }^{19,29,32,33,35}$ may be situationally specific, may be non-replicable, and/or may not translate to real world crash risk. ${ }^{32}$ The few naturalistic longitudinal studies reported an equivalent or lower crash risk associated with cognitive impairment defined using a variety of measures compared to the risk associated with no impairment. ${ }^{15,21,28,36,37}$ However, these studies suffered from small sample sizes and/or short follow-up time. Investigators and policy-makers have stressed the need for longitudinal cohort studies with large sample sizes and reliable dementia and crash information. ${ }^{17,31}$

State Departments of Motor Vehicles, the National Highway Traffic Safety Administration (NHTSA), medical and neurological associations, and technical and non-technical articles generally support limiting and eventual cessation of driving for individuals with dementia. 18,38-42 Older adults can limit driving, e.g. by taking shorter trips or driving only during the day. Studies on self-reported driving habits show that older drivers with dementia implement the above guidance around limiting or cessation of driving. ${ }^{21,27,43-47}$ Two small studies found that, compared with individuals with a Clinical Dementia Rating (CDR) of 0 (normal cognition), self-reported mileage was $15 \%$ to $42 \%$ lower among those with a CDR of 0.5 (cognitively impaired but not demented), and $46 \%$ to $64 \%$ lower among those with a CDR of 1 (mild dementia). ${ }^{15,21}$ A study of 18 people with dementia and age-matched cognitively normal elderly controls found $45 \%$ lower self-reported weekly mileage among people with dementia. ${ }^{48}$ However, self-reported mileage among older adults is often inaccurate, ${ }^{49}$ and these inaccuracies may be particularly pronounced in those with dementia

This study aimed to compare the risk of motor vehicle crash among older drivers with diagnosed dementia to the risk of crash among older drivers without dementia using data on cognition and crash routinely generated and collected from administrative sources.

\section{Methods}

This was a retrospective cohort study examining crash risk for licensed individuals 65-79 years of age with a diagnosis of dementia, compared to crash risk for those without a diagnosis of dementia. 


\section{1 Participants}

Study participants were Washington state residents, 65 to 79 years of age between January 1, 2003 and December 31, 2009, and enrolled at Group Health (GH), a large Washington State consumer-governed health maintenance organization ${ }^{50,51}$ (now part of Kaiser Permanente), for at least one year between January 1, 2003 and December 31, 2009. GH covers approximately 600,000 enrollees in Washington State and Idaho, who broadly resemble Washington State residents with respect to age, sex, and race. ${ }^{51}$ Washington State uses a combination of letters from drivers' names and numbers derived from their birth years to generate driver license numbers. We used Group Health member names and birth years to derive driver license numbers, as we have done previously. ${ }^{51-53}$ We merged GH electronic health records with licensure data from the State Department of Licensing and policereported crash data from the State Department of Transportation. Participants were restricted to those with an active Washington State driving license, including those with commercial or motorcycle license.

\section{2. Data}

2.2.1 Diagnosis of dementia-Dementia status was classified using diagnosis codes and prescription records from the electronic health record. The date of diagnosis was assigned as the earlier of (1) the earliest dementia-related International Classification of Diseases, Ninth Revision, Clinical Modification (ICD-9-CM) diagnosis code recorded in a medical claim or (2) the earliest prescription for an anti-dementia medication [donepezil (Aricept ${ }^{\circledR}$ ) or memantine (Namenda $\left.\left.{ }^{\circledR}\right)\right]$. GH has a prescription drug formulary that does not permit use of these medications to treat mild cognitive impairment. ICD-9-CM diagnosis codes indicating Alzheimer's disease and similar dementias were 294.1, 294.10, 294.11, 294.8, 331, 331.0, 331.1, 331.11, 331.19, 331.2, 331.7, 331.82, 331.89, 331.9, and 294 (Appendix A). Senile dementia and vascular dementia (ICD-9-CM codes 290.0-290.9) were not included in the case definition as codes for these diagnoses were not made available to the study team for analyses. Individuals could be diagnosed with dementia during or before the study.

Exposure and outcome ascertainment began in January 2003, with medical record and prescription data from 1999-2002 serving as a pre-study period during which diagnosis information was gathered. We divided individuals into three groups: (1) patients with no diagnosis of dementia within four years prior to the study and during the study period (1999-2009); (2) patients diagnosed with dementia within the 4-year period prior to the study (1999-2002), (3) patients diagnosed with dementia during the study period (20032009).

2.2.2 Crashes-The outcome was any motor vehicle crash (including passenger vehicles, motorcycles, and commercial vehicles) on a non-private road within Washington State reported by or to police or Washington State Patrol. ${ }^{51}$ Within Washington State, if a law enforcement officer does not attend, investigate, and/or report a crash at the scene, participants must report crashes involving any injury and/or more than $\$ 1000$ in property damage, including vehicle damage. ${ }^{54,55}$ 
2.2.3. Covariates-Additional covariates in the analytic dataset were age and calendar year at study entry, sex, comorbidities, diagnosis of depression, alcohol use disorders recorded in the electronic medical record, and certain classes of medications associated with crash risk. For each participant, the Charlson comorbidity index was calculated at study entry with a lookback period of one year. The index accounted for chronic comorbidities including myocardial infarction, chronic pulmonary disease, diabetes, and AIDS. ${ }^{56}$

Although the Charlson comorbidity index adjusts for dementia, there is no overlap between the ICD-9-CM codes identifying dementia within the index (senile and vascular dementias, 290.0-290.9) and the codes available in this data set. Depression and alcohol consumption have been shown to increase crash risk, including among older drivers. ${ }^{57}$ We used ICD-9$\mathrm{CM}$ codes as proxy measures to identify diagnoses of alcohol-related illness (codes 303 to 303.96) (58,59 $^{5}$ and depression (codes 296 to 296.9 , and 300 to 300.94 ). ${ }^{60} \mathrm{We}$ did not have data on marital status, visual measures, or retirement.

We controlled for potential confounding from four medication classes associated with higher crash risk: sedatives, benzodiazepines, opioids, and antipsychotics. ${ }^{38,61}$ Individuals were considered exposed to each medication class if two or more prescriptions were filled within any four-month period. Among participants diagnosed with dementia during the study, this exposure to medication was assessed separately for the time periods before and after dementia diagnosis.

\subsection{Data analysis}

We estimated the risk of crash as a hazard ratio (HR) and 95\% confidence interval (CI) using a Cox proportional hazards model where the exposure of interest was dementia diagnosis. We used the Anderson-Gill approach to account for recurrent crashes. ${ }^{62,63}$ We incorporated time-varying exposure status (dementia diagnosis) and robust standard errors. We censored subjects at death, disenrollment in GH, study end, loss of or failure to renew driver license, or at age 80. The age limitation was a requirement from the Institutional Review Board (IRB) due to privacy concerns. We tested the proportional hazards assumption using Schoenfeld residual-based plots and tests; the assumption was satisfied for all models.

\subsection{Sensitivity analyses}

We conducted three additional analyses to check the robustness of our exposure measurement. All three used Cox proportional hazards models adjusted for the same covariates as the primary model.

First, we theorized that individuals in non-urban areas may have greater need to drive due to diminished availability of resources within walking distance (e.g. grocery stores and health care facilities) ${ }^{64,65}$ and decreased availability and thus use of public transit. ${ }^{66} \mathrm{We}$ performed stratified analyses based on Rural-Urban Commuting Area (RUCA) codes, which measure the degree of rurality for U.S. census tracts based on measures including urbanization, population density, population size, and proportion of the population commuting to a more urban area ${ }^{64}$ These measures have been cross-walked to ZIP codes. We analyzed individuals residing in a metropolitan core areas (RUCA score of 1) separately from those living in a 
ZIP code with a RUCA score between 2 and 10 (i.e. metropolitan area with high commuting, micropolitan areas, small towns, and rural areas). ${ }^{67}$

Second, we examined crash risk among older drivers with incident dementia to minimize variation related to disease severity. For this analysis, we used an inception study design. ${ }^{68}$ The inception study design may also reduce the risk of miscategorization of the cognitive state by excluding the pre-diagnosis time period when cognitive impairment may have been present. We compared the rate of crash for group 1 (no dementia diagnosis) to the rate of crash in the post-diagnosis period for group 3 (drivers diagnosed with dementia during the study); for this analysis, we excluded the people who were diagnosed with dementia immediately before the study (group 2).

Third, we hypothesized that a high-risk crash period exists immediately prior to the formal diagnosis of dementia. During this period, an individual may have impaired driving but may not yet have restricted driving behaviors. We limited this analysis to incident cases (group 3drivers diagnosed with dementia during the study) and, using a cross-over design, explored whether the diagnosis of dementia was associated with a change in crash risk, using the timeframe from one year before diagnosis until one year after diagnosis. This analysis also accounted for severity by using only the year immediately after diagnosis; dementia does not typically progress rapidly within a year of diagnosis.

We used Stata, Version 13.1 (StataCorp, College Station, TX) for all analyses. This study was approved by the Group Health Research Institute's Human Subjects Review Board.

\section{Results}

\subsection{Study demographic characteristics}

Among 29,730 individuals meeting our inclusion criteria, 827 were diagnosed with dementia before the study start date and another 886 were diagnosed during the study. Individuals diagnosed with dementia before or during the study were older on average at the start of the study, had more co-morbid conditions, and higher proportions had an ICD-9-CM code indicating alcoholism or depression (Table 1). The groups did not differ significantly by sex. Among those with dementia, $65 \%$ died during the study, compared to $24 \%$ of those without dementia.

significant difference between groups 2 and 3 (P-value<0.05)

The overall crash rate was 14.7 crashes per 1,000 person-years. There were 32 crashes over 3,546 years of study time following dementia diagnosis, or 9.0 crashes per 1,000 personyears. 1,385 crashes occurred among individuals without a diagnosis of dementia or in the period prior to diagnosis during 88,143 years of study time, or 15.7 crashes per 1,000 person-years. Among individuals who crashed, eight crashed three times during the study, 103 crashed twice, and the remainder crashed once. Seven crashes involved fatalities. 


\subsection{Primary analysis results}

In our primary analyses, the unadjusted HR of crash after dementia diagnosis (diagnosed during or before the study) was 0.55 (95\% CI 0.33, 0.89). In a multivariate model adjusted for demographic variables and comorbidities, the HR for the association between diagnosed dementia and police-reported crash was 0.56 (95\% CI 0.33,0.94) (Table 2). Males had a significantly higher risk of crash relative to females, as did individuals with an ICD-9-CM code for depression compared to those without.

\subsection{Sensitivity analyses}

3.3.1. Urban and rural analysis results-We identified 3,340 participants living in metropolitan core areas, and 6,383 in less urban areas or rural areas. Among older drivers living in metropolitan core areas, the adjusted hazard ratio of crash among those with a dementia diagnosis, compared to those without a dementia diagnosis, was 0.50 (95\% CI $0.28,0.91$ ) (Figure 1). Among those with less urban to rural residences, individuals with a dementia diagnosis, compared with individuals without a dementia diagnosis, had an adjusted hazard ratio of crash of 0.88 (95\% CI 0.30, 2.62). There was no statistically significant interaction between urbanicity and dementia in relation to risk of crash.

3.3.2 Inception design analysis results-We estimated the risk of crash immediately following dementia diagnosis using data from those diagnosed during the study (group 3) compared to those never diagnosed (group 1) using an inception design. Adjusted for age, co-morbidities, depression, alcohol use, and medication use, the risk of crash was similar to the rate found in our primary analyses, though this did not reach statistical significance (HR $=0.60,95 \%$ CI $0.35,1.02$ ) (Figure 1$)$.

3.3.3. One year pre- and post- diagnosis analysis results-We found no association between dementia diagnosis and crash risk during the year following diagnosis of dementia ( $\mathrm{HR}=1.07,95 \% \mathrm{CI} 0.19,5.99$ ) compared to up to one year prior to diagnosis among those diagnosed during the study (group 3) (Figure 1).

\section{Discussion}

Our primary findings suggest that patients with dementia have a lower risk of crash compared to those without dementia. This finding may initially seem counter-intuitive, as prior research has indicated that drivers with cognitive impairment have poor performance on road tests and simulated driving scenarios. ${ }^{3,15,18,19,21,23-27}$ We suspect the discrepancy between our findings and those expected based on prior studies documenting the impacts of impaired cognition on driving performance may be related to our lacking data on miles driven.

Other longitudinal observational studies that lacked data on driving exposure similarly did not find a higher crash risk associated with cognitive impairment. ${ }^{27,28}$ In a relatively large international study ${ }^{28}$ the crash risk appeared to be lower among people with more advanced stages of dementia. Studies using medical records and police-reported crash data from Western Australia and Quebec found a lower risk of crash among individuals with dementia 
compared to those without dementia. ${ }^{35,36}$ None of these studies showing a protective effect of dementia accounted for exposure to driving. A study with 38 participants reported a lower crash rate among those with a Clinical Dementia Rating (CDR) of 0, compared to a CDR of 0.5 and 1 (cognitively impaired with no dementia and mild Alzheimer's disease), adjusted for self-reported weekly mileage. ${ }^{15}$ We suspect that our findings, which demonstrated lower crash risk for people diagnosed with dementia, reflect purposeful changes in driving habits among some older adults diagnosed with dementia, or changes imposed by families or caregivers. ${ }^{38,69-71}$ Our results suggest that exposure to driving among licensed drivers may differ by dementia status, and that lower driving exposure among older drivers with dementia may more than offset the higher risk associated with impaired decline in driving abilities.

We looked for but did not find evidence to support temporal changes in crash risk. Results from our inception design analyses were similar to those from our primary analyses, which suggests that older drivers with newly acquired dementia diagnoses had a similar crash risk as older drivers with established dementia diagnoses. We also did not see differences in crash rates from the year immediately prior to and the year immediately following dementia diagnosis. Research using large numbers of older drivers that captures driving exposure is needed to better characterize crash risk related to the onset of dementia

Many studies have used licensure status to adjust for exposure to driving in older driver and cognition research. ${ }^{15,19-21,27,72-80}$ We used this same approach. The lower risk we found associated with dementia diagnosis suggests that licensure status alone may not be sufficient to account for exposure to driving. Data on exposure to driving may be quantitative, such as vehicle miles traveled, or qualitative, such as data on driving circumstances, familiarity with the route, or weather. ${ }^{17,31}$ The authors of previous studies have called for large, longitudinal studies to help elucidate relationships between dementia and crash risk. ${ }^{17,31}$ Our findings suggest that data that includes some indication of driving exposure may be necessary.

Future research on driving habits among older adults may consider technologic approaches to accurately measure driving time and distance in addition to driving skill and crash risk. Cell phone applications, in-vehicle technology such as cameras, accelerometers, and yaw rate sensors, or personal actigraphs may present important opportunities to assess older adult driving habits.

As hypothesized, we found a lower risk of crash among urban-dwelling older adults with dementia, but not among suburban or rural residents. The relevance of rural versus urban setting has not previously been explored in research on relationships between cognitive impairment and crash risk. It may be easier for urban dwellers to reduce their exposure to driving due to availability of public transportation and support services (e.g., grocery delivery services). For older adults with dementia, crash risk may be further reduced with extension of services that support reduced driving exposure.

Results from the sensitivity analyses using an inception design and using only individuals diagnosed during the study did not show a relationship between new diagnosis of dementia 
and crash risk. However, there were few crashes recorded among drivers with dementia, which limited power to find differences.

Within the primary analysis, we additionally identified a higher crash risk among individuals diagnosed with depression and among males that was independent of dementia status. Both of these findings agree with previous research around older drivers. 5,36 The majority of individuals had zero comorbidities as identified by the Charlson. It is possible the number of individuals with zero comorbidities is due to the capture period. It could also originate because the comorbidities captured in the Charlson are relatively severe, and with this population of "younger" older drivers, these conditions (and diagnoses) may not have occurred.

\subsection{Limitations}

The study's main limitation is that we did not have information on exposure to driving beyond our inclusion criterion that all participants had an active driver license. Data on driving exposure would allow us to confirm that reduced exposure to driving is the reason for the observed lower hazard. An older adult may renew a license for identification purposes without intending to drive. In addition, study participants may voluntarily curtail driving before license renewal dates.

Three further limitations related to the study's definition of dementia. Despite the relatively large sample size and a long period of follow-up, both the exposure (dementia) and the outcome (crash) were relatively rare, which may have impacted power, particularly within the sensitivity analyses. Additionally, an individual diagnosed with dementia before the study period began, but for whom no dementia diagnosis or dementia-related prescription was noted at subsequent GH interactions, could potentially have been misclassified as not having dementia in our analyses. This concern drove the inception design study, the results of which, while not significant, were similar to those of the main analysis. Finally, this study's operational definition of dementia had two shortcomings: (A) the ICD-9-CM codes related to dementia within the data set were not comprehensive. Notably codes for vascular dementia were not available, and (B) ICD-9-CM codes identifying dementia diagnoses in general and dementia subtypes in particular are notoriously inaccurate. ${ }^{81,82}$ The entire study period preceded the transition to ICD-10. These definitional exclusions limit the generalizability of results to all forms of dementia.

Because of IRB restrictions, we obtained data only for individuals up to age 79. This limits generalizability and may somewhat account for the low prevalence of dementia in the study; 82\% of individuals with Alzheimer's disease are aged 75 or older, an age group that only overlaps by four years with this study sample. Additionally, this study only captures certain types of dementia, notably Alzheimer's disease. Most statistics on the prevalence of dementia do not provide sufficient breakdown to allow for a precise comparison. Within the study, the prevalence of dementia was 5.8\%. Perhaps the closest comparison is the Aging Demographics, and Memory study (ADAMS), a subsample from the Health and Retirement Study (HRS), which found that, using data from 2001-2003, among individuals age 70-79, 10.4\% had Alzheimer's Disease. ${ }^{83} 2012$ data from the HRS showed a prevalence of $4.3 \%$ for all dementia for ages $65-75$ and $10.6 \%$ for ages $75-84 .{ }^{84}$ The HRS assess cognition within a 
research context. Conversely, this study used medical records from a health care delivery system. Early dementia especially may not be recognized in regular clinical care, so there may be people with undiagnosed dementia included as controls in our study. ${ }^{38}$ If dementia was underdiagnosed within this cohort, this misclassification error, in addition to the aforementioned lack of exposure data, biased results toward the null.

Factors other than diminished driving exposure may also contribute to the lower risk of crash we observed among older drivers with dementia. People with dementia may fail to inform police of a crash or may be more likely to have a non-reportable crash. In Washington State, a collision report is not needed if there are no injuries and damages do not exceed $\$ 1000$. Crashes in private parking lots or outside of Washington State are also not included in state Department of Transportation crash data.

Lastly, this data set did not include information about vision. Although all drivers were licensed and therefore had sufficient vision to pass the screening (among those renewing licenses in person), further information on vision was not available.

\subsection{Conclusions}

We linked dementia diagnoses from a large healthcare delivery system with state licensing and crash records. We found that people with dementia diagnoses had lower risks of crash than people without dementia diagnosis. The finding of lower crash risks for people with dementia was especially the case for people living in metropolitan cores. Since cognitive impairment and dementia have repeatedly been found to be associated with riskier driving behavior, we suspect that our findings may reflect inadequate control for exposure to driving.

The older adult population of the U.S. is large and growing rapidly. ${ }^{85}$ As adults age, they face new transportation challenges in meeting social, logistical, and medical needs. Further research around cognition among older drivers is central to informing discussions between care providers, older adults, and families on how to maximize older patients' independence while preserving individual and public safety.

\section{Acknowledgments}

Funding source: Dr. Fraade-Blanar was supported by the National Center for Advancing Translational Sciences, National Institutes of Health, Award Number TL1TR000422. The content is solely the responsibility of the authors and does not necessarily represent the official views of the National Institutes of Health.

\section{References}

1. NHTSA. [Accessed August 10, 2015] Traffic safety facts 2015 data: older population. http://wwwnrd.nhtsa.dot.gov/Pubs/811659.pdf. Published 2017

2. Martin A, Marottoli R, O’Neill D. Driving assessment for maintaining mobility and safety in drivers with dementia (review). Cochrane Database Syst Rev. 2011; (10)

3. Breen DA, Breen DP, Moore JW, Breen PA, O’Neill D. Driving and dementia. Br Med J. 2007; 334(7608):1365-1369. [PubMed: 17600026]

4. Freeman EE, Gange SJ, Munoz B, West SK. Driving status and risk of entry into long-term care in older adults. Am J Public Health. 2006; 96(7):1254-1259. DOI: 10.2105/AJPH.2005.069146 [PubMed: 16735633] 
5. IIHS. [Accessed July 31, 2016] Fatality Facts: Older people. http://www.iihs.org/iihs/topics/t/olderdrivers/fatalityfacts/older-people. Published 2016

6. Alvarez FJ, Fierro I. Older drivers, medical condition, medical impairment and crash risk. Accid Anal Prev. 2008; 40(1):55-60. DOI: 10.1016/j.aap.2007.04.001 [PubMed: 18215532]

7. Li G, Braver ER, Chen L-H. Fragility versus excessive crash involvement as determinants of high death rates per vehicle-mile of travel among older drivers. Accid Anal Prev. 2003; 35(2):227-235. [PubMed: 12504143]

8. Horswill M, Marrington S, McCullough C, et al. The hazard perception ability of older drivers. J Gerontol. 2008; 63(4):P212-P218.

9. Withaar F, Brouwer W, van Zomeren A. Fitness to drive in older drivers with cognitive impairment. JINS J Int Neuropsychol Soc. 2000; 6(4):480-490. [PubMed: 10902417]

10. Anstey KJ, Wood J, Lord S, Walker JG. Cognitive, sensory and physical factors enabling driving safety in older adults. Clin Psychol Rev. 2005; 25(1):45-65. DOI: 10.1016/j.cpr.2004.07.008 [PubMed: 15596080]

11. Alzheimer's Association. 2012 Alzheimer's Disease: Facts and Figures. 2012

12. Snellgrove, CA. Cognitive Screening for the Safe Driving Competence of Older People with Mild Cognitive Impairment or Early Dementia. Canberra: 2005.

13. Dickerson BC, Sperling R, Hyman BT, Albert MS, Blacker D. Clinical prediction of Alzheimer disease dementia across the spectrum of mild cognitive impairment. Arch Gen Psychiatry. 2007; 64(12):1443-1450. DOI: 10.1001/archpsyc.64.12.1443.Clinical [PubMed: 18056553]

14. Alzheimer's Association. [Accessed July 27, 2017] Alzheimer's disease facts and figures. 2013. http://www.alz.org/downloads/facts_figures_2013.pdf. Published 2013

15. Ott BR, Heindel WC, Papandonatos GD, et al. A longitudinal study of drivers with Alzheimer disease. Neurology. 2008; 70(14):1109.

16. Dawson JD, Anderson SW, Uc EY, Dastrup E, Rizzo M. Predictors of driving safety in early Alzheimer disease. Neurology. 2009; 72(6):521-527. DOI: 10.1212/01.wnl.0000341931.35870.49 [PubMed: 19204261]

17. Wagner JT, Müri RM, Nef T, Mosimann UP. Cognition and driving in older persons. Swiss Med Wkly. 2011 Jan.140doi: 10.4414/smw.2011.13136

18. Carr D, Ott BR. The older adult driver with cognitive impairment. J Am Med Assoc. 2010 Jan. 303:1632-1641. 2009. DOI: 10.1001/jama.2010.481

19. Rizzo M, McGehee DV, Dawson JD, Anderson SN. Simulated car crashes at intersections in drivers with Alzheimer disease. Alzheimer Dis Assoc Disord. 2001; 15(1):10-20. [PubMed: 11236820]

20. Owsley C, Ball K, Sloane ME, Roenker DL, Bruni JR. Visual/cognitive correlates of vehicle accidents in older drivers. Psychol Aging. 1991; 6(3):403-415. [PubMed: 1930757]

21. Carr D, Duchek J, Morris J. Characteristics of motor vehicle crashes of drivers with dementia of the Alzheimer type. J Am Geriatr Soc. 2000; 48(1)

22. Barco PP, Baum CM, Ott BR, et al. Driving errors in persons with dementia. J Am Geriatr Soc. 2015; 63(7):1373-1380. DOI: 10.1111/jgs.13508 [PubMed: 26140521]

23. Ball KK, Roenker DL, Wadley VG, et al. Can high-risk older drivers be identified through performance-based measures in a Department of Motor Vehicles setting? J Am Geriatr Soc. 2006; 54(1):77-84. [PubMed: 16420201]

24. Carr D. Motor vehicle crashes and drivers with DAT. Alzheimer Dis Assoc Disord. 1997; 11(1): $38-41$.

25. Lincoln N, Radford K, Lee E. The assessment of fitness to drive in people with dementia. Int J Geriatr Psychiatry. 2006 Sep.:1044-1051. [PubMed: 16955424]

26. Jones Ross RW, Scialfa CT, Cordazzo STD. Predicting on-road driving performance and safety in cognitively impaired older adults. J Am Geriatr Soc. 2015; 63:2356-2369. DOI: 10.1111/jgs. 13712

27. Duchek JM, Carr DB, Hunt L, et al. Longitudinal driving performance in early-stage dementia of the Alzheimer type. J Am Geriatr Soc. 2003; 51(10):1342-1347. [PubMed: 14511152] 
28. Joseph PG, O’Donnell MJ, Teo KK, et al. The Mini-Mental State Examination, clinical factors, and motor vehicle crash risk. J Am Geriatr Soc. 2014; 62:1419-1426. DOI: 10.1111/jgs.12936 [PubMed: 25040793]

29. Marino M, de Belvis A, Basso D, et al. Interventions to evaluate fitness to drive among people with chronic conditions: Systematic review of literature. Accid Anal Prev. 2012; 50:377-396. [PubMed: 22658463]

30. Fitten L, Perryman K, Wilkinson C, et al. Alzheimer and vascular dementias and driving: a prospective road and laboratory study. JAMA. 1995; 273(17):1360-1365. DOI: 10.1001/jama. 2013.5184 [PubMed: 7715061]

31. Molnar FJ, Patel A, Marshall SC, Man-Son-Hing M, Wilson KG. Systematic review of the optimal frequency of follow-up in persons with mild dementia who continue to drive. Alzheimer Dis Assoc Disord. 2006; 20(4):295-297. [PubMed: 17132976]

32. Charlton J, Koppel S, Odell M, et al. Influence of chronic illness on crash involvement of motors vehicle drivers (2). 2010

33. Martin AJA, Marottoli R, O’Neill D. Driving Assessment for Maintaining Mobility and Safety in Drivers with Dementia. 2013; 5doi: 10.1002/14651858.CD006222.pub3

34. Rapoport MJ, Sukhawathanakul P, Naglie G, et al. Cognitive performance, driving behavior, and attitudes over time in older adults. Can J Aging / La Rev Can du Vieil. 2016:1-11.

35. Anderson SW, Rizzo M, Shi Q, Uc EY, Dawson JD. Cognitive abilities related to driving performance in a simulator and crashing on the road. Third Int Driv Symp Hum Factors Driv Assessment, Train Veh Des. 2004:286-292.

36. Dow J, Gaudet M, Turmel E. Crash rates of quebec drivers with medical conditions. Ann Adv Automot Med. 2013; 57:57-66. [PubMed: 24406946]

37. Meuleners LB, Ng J, Chow K, Stevenson M. Motor vehicle crashes and dementia: A populationbased study. J Am Geriatr Soc. 2016; :1039-1045. DOI: 10.1111/jgs.14109 [PubMed: 27171906]

38. American Geriatrics Society. Pomidor, A., editor. AGS/NHTSA. Clinician's Guide to Assessing and Counseling Older Driver. 3. Washington, DC: 2016.

39. Dickerson AE. Driving with dementia: evaluation, referral, and resources. Occup Med (Lond). 2014 Nov.28:62-76. 2013.

40. Tung EE, Chen CYY, Takahashi PY. Common curbsides and conundrums in geriatric medicine. Mayo Clin Proc. 2013; 88(6):630-635. DOI: 10.1016/j.mayocp.2013.03.017 [PubMed: 23726402]

41. The Hartford. Your road ahead: a guide for comprehensive driving evaluation. http:// www.thehartford.com/sites/thehartford/files/1287779439728.pdf. Published 2010

42. AAN. Driving with dementia: understanding the safety risks. American Academy of Neurology.

43. Seiler S, Schmidt H, Lechner A, et al. Driving cessation and dementia: results of the prospective registry on dementia in Austria (PRODEM). PLoS One. 2012; 7(12):e52710.doi: 10.1371/ journal.pone.0052710 [PubMed: 23300746]

44. Edwards JD, Ross, Lesley A, Ackerman ML, et al. Longitudinal predictors of driving cessation among older adults from the ACTIVE clinical trial. J Gerontol. 2008; 63(1):6-12.

45. Lyman JM, McGwin G, Sims RV. Factors related to driving difficulty and habits in older drivers. Accid Anal Prev. 2001; 33(3):413-421. [PubMed: 11235803]

46. Braitman, Ka, McCartt, AT. Characteristics of older drivers who self-limit their driving. Ann Adv Automot Med / Annu Sci Conf Assoc Adv Automot Med. 2008 Oct.52:245-254.

47. Stutts J. Do older drivers with visual and cognitive impairments drive less? J Am Geriatr Soc. 1998; 46(7):854-861. [PubMed: 9670872]

48. Festa EK, Ott BR, Manning KJ, Davis JD, Heindel WC. Effect of cognitive status on selfregulatory driving behavior in older adults: an assessment of naturalistic driving using in-car video recordings. J Geriatr Psychiatry Neurol. 2013; 26(1):10-18. DOI: 10.1177/0891988712473801 [PubMed: 23385363]

49. O'Connor ML, Edwards JD, Bannon Y. Self-rated driving habits among older adults with clinically-defined mild cognitive impairment, clinically-defined dementia, and normal cognition. Accid Anal Prev. 2013; 61:197-202. [PubMed: 23769114] 
50. Ehlenbach W, Hough C. Association between acute care and critical illness hospitalization and cognitive function in older adults. JAMA. 2010; 303(8):763-770. [PubMed: 20179286]

51. Hansen RN, Boudreau DM, Ebel BE, Grossman DC, Sullivan SD. Sedative hypnotic medication use and the risk of motor vehicle crash. Am J Public Health. 2015; 105(8):64-69.

52. Gallian JA. Assigning Driver's License Numbers. Math Mag. 1991; 64(1):13-22.

53. Hansen RN, Walker RL, Shortreed SM, et al. Impact of an opioid risk reduction initiative on motor vehicle crash risk among chronic opioid therapy patients. Pharmacoepidemiol Drug Saf. 2017; 26(1):47-55. DOI: 10.1002/pds.4130 [PubMed: 27862597]

54. Washington State Legistature. RCW 46.52.030.

55. WSP. [Accessed June 19, 2017] What to do if you are involved in a minor collision. Washington State Patrol. http://www.wsp.wa.gov/mweb/m_collision.htm

56. Charlson M, Pompei P, Ales K. A new method of classifying prognostic comorbidity in longitudinal studies: Development and validation. J Chronic Dis. 1987; 40(5):373-383. [PubMed: 3558716]

57. Sims RV, McGwin GJ, Allman RM, Ball KK, Owsley C. Exploratory study of incident vehicle crashes among older drivers. Journals Gerontol - Ser A Biol Sci Med Sci. 2000; 55(1):M22-M27. DOI: $10.1093 /$ gerona/55.1.M22

58. Rehm J, Gmel G, Sempos CT, Trevisan M. Alcohol-related morbidity and mortality. Alcohol Res Health. 2003; 27(1):39-51. [PubMed: 15301399]

59. Kilbourne BJ, Cummings SM, Levine R. Alcohol diagnoses among older Tennessee Medicare beneficiaries: Race and gender differences. Int J Geriatr Psychiatry. 2012; 27(5):483-490. DOI: 10.1002/gps.2740 [PubMed: 21618286]

60. Egede LE, Walker RJ, Bishu K, Dismuke CE. Trends in costs of depression in adults with diabetes in the United States: Medical expenditure panel survey, 2004-2011. J Gen Intern Med. 2016; : 2004-2011. DOI: 10.1007/s11606-016-3650-1

61. Gibson JE, Hubbard RB, Smith CJP, Tata LJ, Britton JR, Fogarty AW. Use of self-controlled analytical techniques to assess the association between use of prescription medications and the risk of motor vehicle crashes. Am J Epidemiol. 2009; 169(6):761-768. [PubMed: 19181876]

62. Andersen P, Gill R. Cox's regression model for counting processes: a large sample study. Ann Stat. 1982; 10(4):1100-1120.

63. Kelly, Patrick J, Lim LL-Y. Survival analysis for recurrent event data: an application to childhood infectious diseases. Stat Med. 2006; 19(1):13-33. DOI: 10.1002/sim.2362

64. Inagami S, Gao S, Karimi H, Shendge MM, Probst JC, Stone RA. Adapting the Index of Relative Rurality (IRR) to Estimate Rurality at the ZIP Code Level: A Rural Classification System in Health Services Research. J Rural Heal. 2015; 0:1-9. DOI: 10.1111/jrh.12148

65. Todd K, Ullrich F, Mueller K. Rural pharmacy closures: implications for rural communities. Rural Policy Brief. 2013; 5:1-4.

66. Fan JX, Wen M, Kowaleski-Jones L. Sociodemographic and environmental correlates of active commuting in rural america. J Rural Heal. 2015; 31(2):176-185. DOI: 10.1111/jrh.12084

67. USDA. [Accessed January 27, 2016] Rural-Urban Commuting Area Codes. http:// www.ers.usda.gov/data-products/rural-urban-commuting-area-codes.aspx. Published 2014

68. Bernard T, Armstrong-Wells J, Goldenberg N. The Institution-Based Prospective Inception Cohort Study: Design, Implementation, and Quality Assurance in Pediatric Thrombosis and Stroke Research. Semin Thromb Hemost. 2013; 39(1):10-14. DOI: 10.1086/498510.Parasitic [PubMed: 23269572]

69. The Hartford. [Accessed December 1, 2016] Enhancing safety and comfort for mature drivers: research results. http:/www.thehartford.com/sites/thehartford/files/ TopCarTechnologiesInfographic.pdf. Published 2016

70. The Hartford. At the crossroads: family conversations about Alzheimer's disease, dementia, and driving. http://hartfordauto.thehartford.com/UI/Downloads/Crossroads.pdf. Published 2010

71. The Hartford. [Accessed July 31, 2016] We need to talk: Family conversations with older drivers. http://hartfordauto.thehartford.com/UI/Downloads/FamConHtd.pdf 
72. Vance DE, Roenker DL, Cissell GM, Edwards JD, Wadley VG, Ball KK. Predictors of driving exposure and avoidance in a field study of older drivers from the state of Maryland. Accid Anal Prev. 2006; 38(4):823-831. [PubMed: 16545765]

73. Cheung I, McCartt AT. Declines in fatal crashes of older drivers: changes in crash risk and survivability. Accid Anal Prev. 2011; 43(3):666-674. [PubMed: 21376853]

74. Staplin L, Gish KW, Wagner EK. MaryPODS revisited: Updated crash analysis and implications for screening program implementation. J Safety Res. 2003; 34(4):389-397. [PubMed: 14636661]

75. Sims RV, Owsley C, Allman RM, Ball K, Smoot TM. A preliminary assessment of the medical and functional factors associated with vehicle crashes by older adults. J Am Geriatr Soc. 1998; 46(5): 556-561. [PubMed: 9588367]

76. Lundberg C, Hakamies-Blomqvist L. Impairments of some cognitive functions are common in crash-involved older drivers. Accid Anal Prev. 1998; 30(3)

77. Hakamies-Blomqvist L. Older drivers' accident risk: conceptual and methodological issues. Accid Anal Prev. 1998; 30(3):293-297. [PubMed: 9663287]

78. Owsley C, G M Jr, Ball K. Vision impairment, eye disease, and injurious motor vehicle crashes in the elderly. Ophthalmic Epidemiol. 1998; 5(2):101-114. [PubMed: 9672910]

79. Rapoport MJ, Naglie G, Weegar K, et al. The relationship between cognitive performance, perceptions of driving comfort and abilities, and self-reported driving restrictions among healthy older drivers. Accid Anal Prev. Mar.2013

80. Ball K, Owsley C, Stalvey B, Roenker DL, Sloane ME, Graves M. Driving avoidance and functional impairment in older drivers. Accid Anal Prev. 1998; 30(3):313-322. [PubMed: 9663290]

81. McDavid A, Crane PK, Newton KM, et al. Enhancing the power of genetic association studies through the use of silver standard cases derived from electronic medical records. PLoS One. 2013; 8(6)doi: 10.1371/journal.pone.0063481

82. Kho AN, Pacheco JA, Peissig PL, et al. Electronic medical records for genetic research: results of the eMERGE consortium. Sci Trans Med. 2011; 3(79):1-14. DOI: 10.1126/scitranslmed. 3001807.Electronic

83. Plassman BL, Langa KM, Fisher GG, et al. Prevalence of dementia in the United States: The aging, demographics, and memory study. Neuroepidemiology. 2007; 29(1-2):125-132. DOI: 10.1159/000109998 [PubMed: 17975326]

84. Langa KM, Larson EB, Crimmins EM, et al. A Comparison of the Prevalence of Dementia in the United States in 2000 and 2012. JAMA Intern Med. 2017; 177(1):51-58. DOI: 10.1001/ jamainternmed.2016.6807 [PubMed: 27893041]

85. NHTSA. Traffic safety facts: older population. http://www-nrd.nhtsa.dot.gov/Pubs/812005.pdf. Published 2014 


\section{Highlights}

- A data set of almost 30,000 drivers age 65 to 79 followed for 7 years was created to examine the effect of dementia diagnosis on crash risk.

- Compared to individuals without dementia, the hazard of crash among those with dementia was almost half.

- $\quad$ This relationship held in urban areas, but not in rural and suburban areas where older drivers may have more need to drive.

- It is hypothesized that these study findings result from unmeasured decreases in driving after dementia diagnosis. 


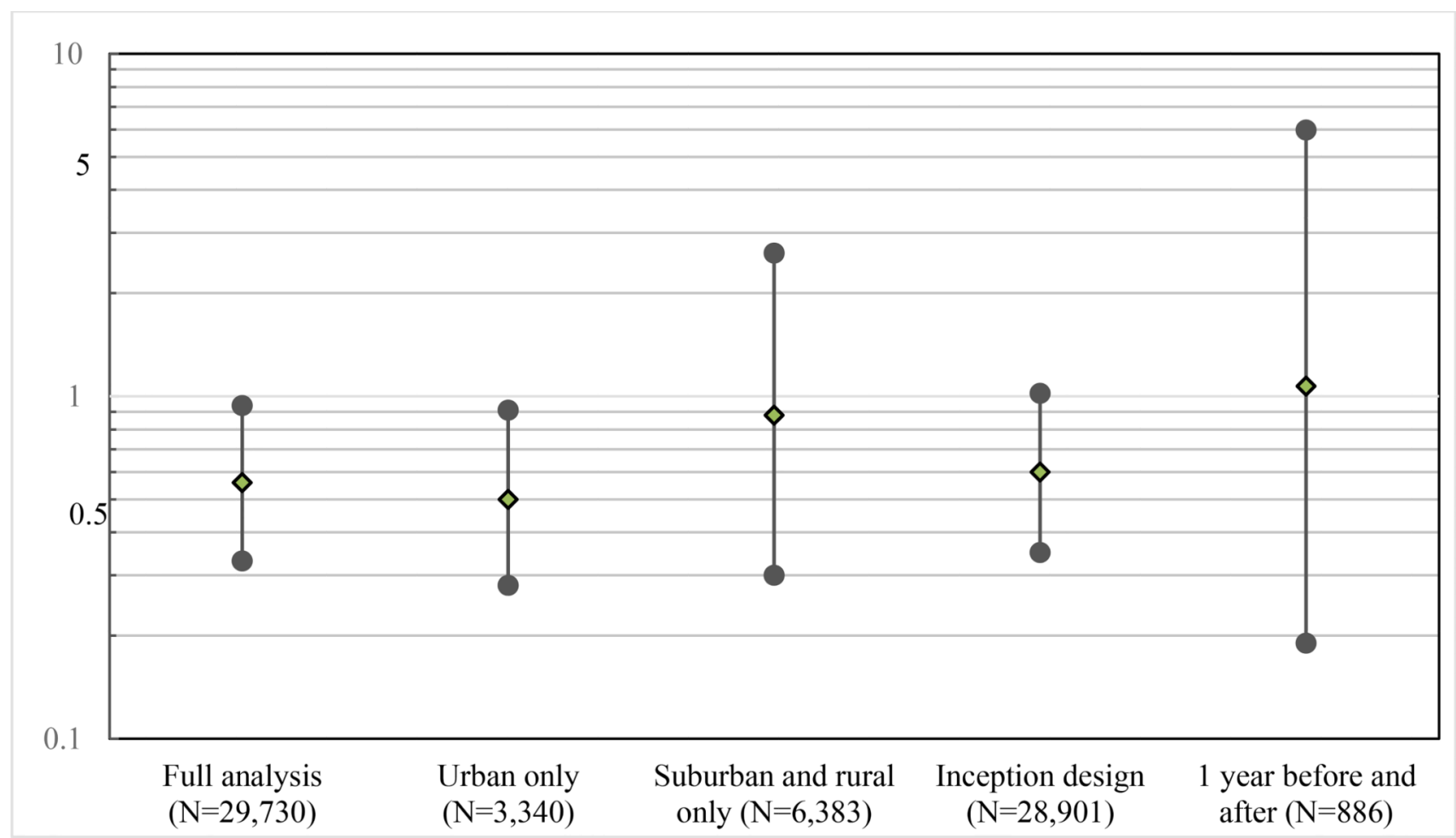

Figure 1.

Sensitivity analyses: results of adjusted hazard rates (aHR) associated with crash (sample size in parentheses) 


\section{로을}

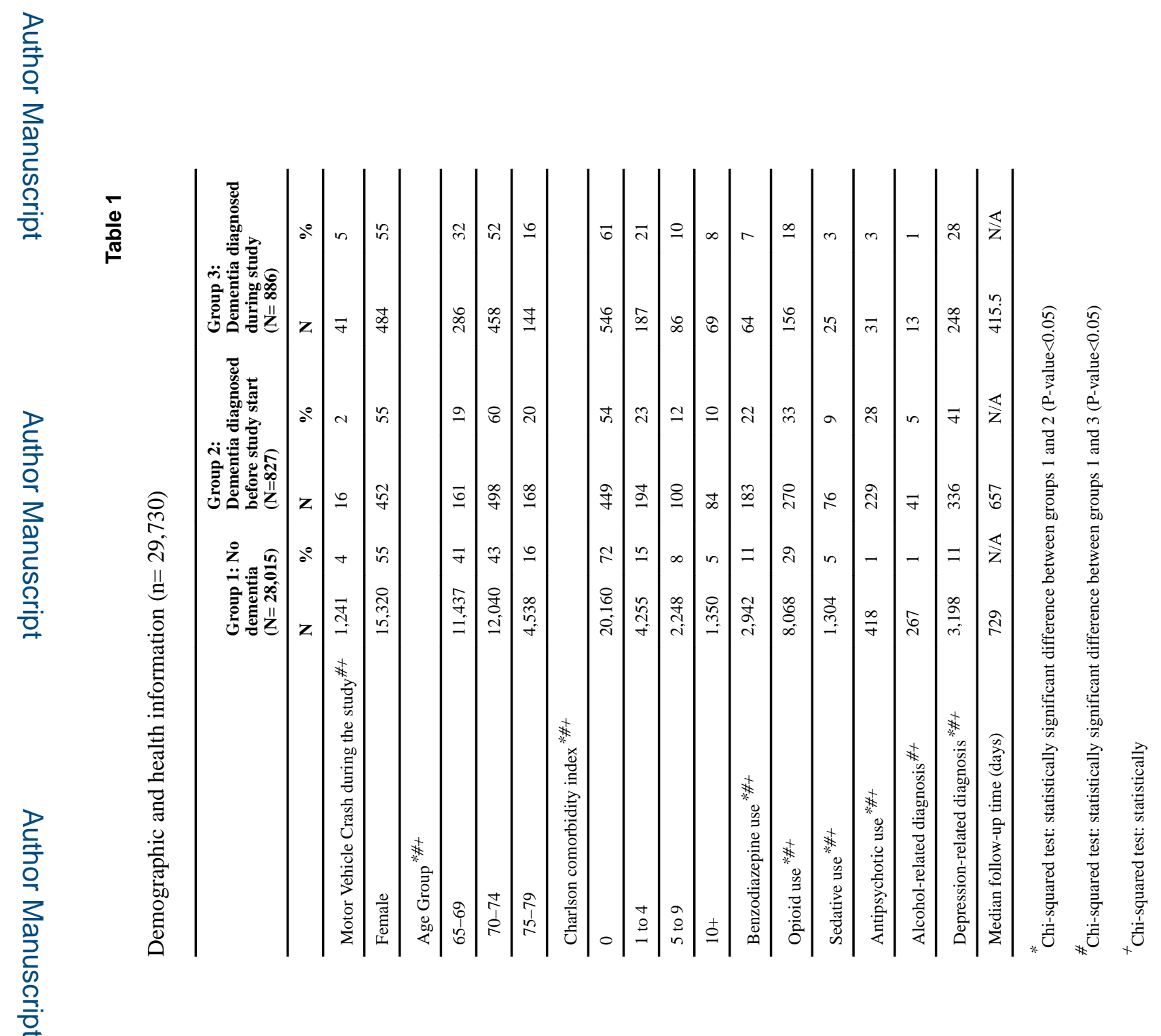




\section{Table 2}

Hazard ratio for police-reported motor vehicle crash in multivariate analysis using data from all study participants

\begin{tabular}{llll}
\hline & $\begin{array}{l}\text { Hazard } \\
\text { ratio }\end{array}$ & $\mathbf{9 5 \%}$ CI & P-value \\
\hline Dementia diagnosis & 0.56 & $0.33,0.94$ & 0.03 \\
\hline Female sex & 0.66 & $0.59,0.73$ & $<0.01$ \\
\hline Age & 0.99 & $0.98,1.01$ & 0.52 \\
\hline Benzodiazepine & 1.07 & $0.90,1.28$ & 0.44 \\
\hline Sedatives & 0.93 & $0.73,1.19$ & 0.57 \\
\hline Opioids & 0.98 & $0.87,1.11$ & 0.80 \\
\hline Antipsychotics & 0.68 & $0.42,1.10$ & 0.12 \\
\hline Alcohol-related diagnosis & 1.26 & $0.82,1.93$ & 0.29 \\
\hline Depression-related diagnosis & 1.20 & $1.02,1.42$ & 0.03 \\
\hline Charlson comorbidity index & & & \\
\hline 0 & Reference category & \\
\hline 1 & 1.16 & $1.00,1.34$ & 0.05 \\
\hline 2 & 0.90 & $0.72,1.13$ & 0.35 \\
\hline $3+$ & 0.96 & $0.72,1.29$ & 0.81 \\
\hline Year of study entry & 0.97 & $0.92,1.02$ & 0.20 \\
\hline
\end{tabular}

